\title{
A disciplina como elemento constitutivo do modo de produção capitalista
}

\author{
Gustavo Meneghetti \\ Universidade Federal de Santa Catarina (UFSC)
}

\author{
Simone Sobral Sampaio \\ Universidade Federal de Santa Catarina (UFSC)
}

\section{A disciplina como elemento constitutivo do modo de produção capitalista}

Resumo: Este artigo tem como objetivo examinar as relações conjuntivas presentes na analítica foucaultiana das relações de poder disciplinar e na análise de Marx sobre o modo de produção capitalista. Para isso utiliza, fundamentalmente, duas obras de Foucault e Marx, respectivamente: Vigiar e Punir e $O$ Capital. Desse modo, identifica como a disciplina constitui dispositivo estratégico ao funcionamento do sistema capitalista.

Palavras-chave: Foucault. Marx. Disciplina. Trabalho. Modo de produção capitalista.

\section{Discipline as a Constitutive Element of the Capitalist Mode of Production}

Abstract: The purpose of this article is to examine the conjunctive relationships present in the Foucaultian analysis of the relations of disciplinary power and in Marx's analysis of the capitalist mode of production. To do so, it focuses on two works by Foucault and Marx, respectively: Discipline and Punish and Capital. It thus identifies how discipline constitutes a device strategic to the operation of the capitalist system

Keywords: Foucault, Marx. Discipline. Work. Capitalist mode of production. 


\section{Introdução}

Enquanto a análise de Marx adota o método dialético, Foucault tem a genealogia. Sem dúvida, o que os aproxima, do ponto de vista metodológico, é o que se pode chamar de historicidade. Para Marx, importa compreender o processo histórico que deu origem a determinado objeto em suas múltiplas determinações materiais de produção, nesse caso, o movimento do capital. Para Foucault, o que interessa é reconstituir as condições históricas que possibilitaram o surgimento de um objeto como efeito destas condições, ou seja, as relações de poder.

Basta uma leitura atenta de uma das principais obras de um e de outro, Das Kapital e Surveiler et Punir, para identificar que a história é a matéria-prima de análise, seja quando analisada a partir de como os homens produzem materialmente sua vida, seja na investigação genealógica das relações de poder disciplinar presentes em determinada relação social.

Partindo dessa aproximação Foucault-Marx, este artigo tem como objetivo examinar as relações conjuntivas presentes na analítica foucaultiana das relações de poder disciplinar e na análise de Marx sobre o modo de produção capitalista. A ideia central indica que a disciplina é um elemento constitutivo e estratégico ao funcionamento do sistema capitalista.

O texto está organizado em três seções. A primeira delas trata de definir o que é a disciplina e quais são seus instrumentos e efeitos na sociedade moderna. A segunda seção aborda a relação entre disciplina e trabalho, mostrando sua funcionalidade para o modo de produção capitalista. Por fim, na terceira seção, o foco é a disciplina como aparelho que serve para capitalizar o tempo dos indivíduos, tornando-os úteis e produtivos.

\section{0 que é disciplina?}

Para se entender a disciplina, no sentido foucaultiano do termo, é preciso reter, antes de tudo, dois pressupostos básicos que orientam as análises do autor de Vigiar e Punir. O primeiro deles: "poder se exerce mais que se possui" (FOUCAULT, 2013, p. 29). Significa que o poder não é uma propriedade ou um privilégio, que pertence a determinados indivíduos, grupos ou mesmo classes sociais, devendo ser concebido como uma estratégia movida por disposições técnicas e táticas. Seria mais adequado, portanto, falar de relações de poder que do poder em si. Foi assim que Foucault investigou a maneira como o sujeito tem o seu próprio corpo investido por relações de poder.

O segundo pressuposto é o seguinte: os mecanismos através dos quais se exerce o poder têm efeitos "positivos" e não puramente repressivos. O poder não busca apenas reprimir, impedir ou obrigar, como se tivesse tão somente um caráter sancionatório. O poder tem sua "utilidade"; ele produz, induz, investe o corpo do sujeito. Daí porque o corpo está mergulhado num campo político:

Este investimento político do corpo está ligado, segundo relações complexas e recíprocas, à sua utilização econômica; é, numa boa proporção, como força de produção que o corpo é investido por relações de poder e de dominação; mas em compensação sua constituição como força de trabalho só é possível se ele está preso num sistema de sujeição (onde a necessidade é também um instrumento político cuidadosamente organizado, calculado e utilizado); o corpo só se torna força útil se é ao mesmo tempo corpo produtivo e corpo submisso (FOUCAULT, 2013, p. 28-29).

Com efeito, a disciplina nada mais é que uma modalidade de exercício de poder ou uma tecnologia de poder, isto é, uma maneira específica segundo a qual uns exercem o poder sobre outros. Ela não é uma inovação recente, tendo se tornado, sobretudo a partir do século XVIII, uma fórmula geral de dominação. "Esses métodos que permitem o controle minucioso das operações do corpo, que realizam a sujeição constante de suas forças e lhes impõem uma relação de docilidade-utilidade, são o que podemos chamar as "disciplinas" (FOUCAULT, 2013, p. 133).

A disciplina, então, é uma espécie de anatomia política, cujo efeito é fabricar corpos dóceis, isto é, ao mesmo tempo, úteis e obedientes. Ela investe sobre o corpo humano, manipulando seus movimentos, gestos, comportamentos, criando nele um modus operandi. Produz, simultaneamente, de um lado, aptidão ou capacidade, e de outro, uma relação de sujeição. Nas palavras de Foucault (2013, p. 133-134): "A disciplina aumenta as forças do corpo (em termos econômicos de utilidade) e diminui essas mesmas forças (em termos políticos de obediência)".

Três são os instrumentos do poder disciplinar. Primeiro, a vigilância hierárquica, um jogo de olhar silencioso e discreto que permite observar, fiscalizar e controlar os indivíduos. Segundo, a sanção normalizadora, uma espécie de micropenalidade que atua no vazio deixado pelas leis, punindo todo e qualquer desvio à regra $\mathrm{e}$ 
buscando "normalizar" o indivíduo. Terceiro, o exame, um mecanismo que liga formação de saber e exercício de poder, dando visibilidade ao indivíduo, documentando-o e fazendo dele um "caso" (FOUCAULT, 2013).

Não é necessário recorrer à violência para disciplinar. Com melhor eficácia ainda, a disciplina pode ser leve e sutil, permitindo uma vigilância generalizada através da extensão progressiva dos seus mecanismos. O Panóptico de Bentham ${ }^{1}$ se apresenta como um modelo generalizável de funcionamento, servindo para vigiar os prisioneiros, cuidar dos doentes, instruir os estudantes, fiscalizar os operários, podendo ser utilizado nas prisões, nos hospitais, nas escolas, nas oficinas. Como sugere Foucault (2013, p. 195): "Cada vez que se tratar de uma multiplicidade de indivíduos a que se deve impor uma tarefa ou um comportamento, o esquema panóptico poderá ser utilizado".

Os mecanismos disciplinares tendem, portanto, a se difundir e se espraiar por todo o corpo social. Eles podem, até mesmo, desinstitucionalizar-se, ou seja, sair das instituições fechadas e circular de modo livre, configurando um verdadeiro panoptismo social. Os grupos religiosos e a polícia, por exemplo, realizam muito bem certas funções disciplinares, agindo como uma rede de disciplinamento da população:

Pode-se então falar, em suma, da formação de uma sociedade disciplinar nesse movimento que vai das disciplinas fechadas, espécie de 'quarentena' social, até o mecanismo indefinidamente generalizável do 'panoptismo'. Não que a modalidade disciplinar do poder tenha substituído todas as outras; mas porque ela se infiltrou no meio das outras, desqualificando-as às vezes, mas servindo-lhes de intermediária, ligando-as entre si, prolongando-as, e principalmente permitindo conduzir os efeitos de poder até os elementos mais tênues e mais longínquos. Ela assegura uma distribuição infinitesimal das relações de poder (FOUCAULT, 2013, p. 204).

Numa palavra, é como se a prisão se estendesse para além da prisão, formando um continuum carcerário por meio da difusão e generalização das técnicas disciplinares. Nesse passo, o poder de punir se torna algo natural e legítimo, exercido sem excessos ou abusos contra todo e qualquer desvio, contra a mais ínfima ilegalidade. A sociedade moderna como que distribui o poder normalizador, havendo vários juízes da normalidade (professor-juiz, médico-juiz, assistente social-juiz etc.), cada qual submetendo o corpo a uma nova economia do poder.

Sem dúvida, a escola representa o exemplo mais típico do poder disciplinar. Nela, prima-se pela produção de uma conduta considerada normal: o aluno assíduo, pontual, dedicado, obediente etc. Cada vez que surge um aluno cujo comportamento se desvia do padrão de normalidade, torna-se necessário e urgente discipliná-lo, quer dizer, transformá-lo num aluno dócil e útil. Tudo isso para que ele seja, no futuro, um homem de bem, honesto, sim, mas fundamentalmente trabalhador e obediente.

Os dispositivos disciplinares atuam justamente para evitar ou diminuir condutas desviantes, fora do padrão da norma. Caso isso ocorra, a punição não só é legítima como obedece ao reforço da disciplina; redisciplinarização é o que sobra como eufemismo da punição. A disciplina, pois, não é o remédio dado pós-conduta transgressora, mas antídoto

No modo de produção capitalista, pois, a disciplina funciona como técnica que fabrica indivíduos úteis ou indivíduos-máquinas. necessário para evitar a saída da regra.

$\mathrm{Na}$ verdade, o sistema educacional como um todo poderia ser pensado na ótica da disciplina. Pense-se, por exemplo, no ensino técnico-profissionalizante, mera instrução sobre o uso da tecnologia e o manuseio produtivo dos instrumentos de trabalho. Uma técnica de adestramento que produz um corpo adaptado ao modo de produção capitalista. Entre a educação e a fábrica existe uma relação muito próxima, uma relação, por assim dizer, de cumplicidade: "Do sistema fabril [...] brota o germe da educação do futuro, que há de conjugar, para todas as crianças a partir de certa idade, o trabalho produtivo com o ensino e a ginástica, não só como forma de incrementar a produção social, mas como único método para a produção de seres humanos desenvolvidos em suas múltiplas dimensões" (MARX, 2013, p. 554).

A mesma lei fabril que limita e regulamenta a jornada de trabalho prevê cláusulas educacionais. $\mathrm{O}$ ensino primário se torna obrigatório, assim como a conjugação do ensino com o trabalho manual; a legislação fabril promove a união entre trabalho e instrução a partir da infância (MARX, 2013). Tudo para produzir operários eficientes que saibam o seu devido lugar, que cooperem entre si, que façam uso lucrativo do tempo, que se sintam vigiados e sujeitos a punições; tudo para fabricar operários treinados, adestrados, enfim, disciplinados. Para Foucault, é preciso ver a disciplina em seu papel positivo ou produtivo, na medida em que ela busca aumentar a utilidade dos indivíduos. Numa fábrica, por exemplo, a disciplina não visa apenas fazer respeitar os regulamentos; mais do que isso, seu propósito é desenvolver as aptidões, melhorar as habilidades, tornar os 
operários mais produtivos. No modo de produção capitalista, pois, a disciplina funciona como técnica que fabrica indivíduos úteis ou indivíduos-máquinas.

\section{A disciplina do trabalho}

O protótipo da disciplina é dado pelo uso da força ou da violência. Um exemplo histórico é a chamada acumulação primitiva que, de acordo com Marx (2013), constitui a pré-história do capital e o ponto de partida do modo de produção capitalista. As condições de emergência da disciplina contaram com a total expropriação dos corpos. Foi a partir de um corpo nu que as técnicas disciplinares atuaram. A sujeição desses novos sujeitos se deu a partir de sua total destituição.

Sabe-se que o capital é uma relação social que põe frente a frente, de um lado, possuidores de dinheiro e meios de produção, e de outro, trabalhadores livres, vendedores de sua própria força de trabalho. Mas para que haja trabalhadores assalariados, é necessário separá-los dos meios de produção e de subsistência, isto é, das condições de realização de seu trabalho. Para se converterem em livres vendedores de sua força de trabalho, os trabalhadores tiveram roubados todos os meios de produção e de existência. "E a história dessa expropriação", diz Marx (2013, p. 787), "está gravada nos anais da humanidade com traços de sangue e fogo".

A chamada acumulação primitiva nada mais é que o processo de expropriação, pela força, dos camponeses e produtores rurais da posse da terra, único modo pelo qual uma massa de trabalhadores livres foi lançada no mercado de trabalho. Nos termos de Marx (2013, p. 787):

Na história da acumulação primitiva, o que faz época são todos os revolucionamentos que servem de alavanca à classe capitalista em formação, mas, acima de tudo, os momentos em que grandes massas humanas são despojadas súbita e violentamente de seus meios de subsistência e lançadas no mercado de trabalho como proletários absolutamente livres. A expropriação da terra que antes pertencia ao produtor rural, ao camponês, constitui a base de todo o processo.

Ao serem expulsos de suas terras, muitos camponeses acabaram se transformando em mendigos, vagabundos, delinquentes etc. Isso levou ao surgimento, na Europa Ocidental, entre o fim do século 15 e o início do século 16, de uma legislação específica contra os pobres. De fato, uma "legislação sanguinária" (MARX, 2013), que previa e autorizava o uso brutal de açoites, as prisões abusivas, o trabalho forçado e, em caso de reincidência, até mesmo as execuções, tudo para obrigar o proletariado livre ao regime de trabalho assalariado.

A esta altura, as condições fundamentais da produção capitalista estavam dadas: possuidores dos meios de produção de um lado, trabalhadores livres de outro. Mas tais condições não bastam por si só. A necessidade, pura e simples, não era suficiente para levar os ditos vagabundos e pobres ao trabalho assalariado. Sem os meios tradicionais de subsistência, ainda assim muitos trabalhadores buscavam formas alternativas de sobrevivência, recusando-se a venderem sua força de trabalho. Era preciso, pois, para eles, uma disciplina, ou melhor, a disciplina do trabalho: "Assim, a população rural, depois de ter sua terra violentamente expropriada, sendo dela expulsa e entregue à vagabundagem, viu-se obrigada a se submeter, por meio de leis grotescas e terroristas, e por força de açoites, ferros em brasa e torturas, a uma disciplina necessária ao sistema de trabalho assalariado" (MARX, 2013, p. 808, grifo nosso).

Além da legislação sanguinária, a burguesia então emergente se utilizou da força do Estado para regular, para baixo, o salário pago ao trabalhador, o que deu origem às leis para compressão dos salários. Era proibido pagar salários acima daquele fixado na lei, bem como era considerado crime toda e qualquer associação de trabalhadores (MARX, 2013). Evidentemente, a legislação era hostil ao trabalhador, punindo-o com rigor em caso de desobediência. Há, aqui, uma relação íntima entre disciplina e exploração do trabalho.

De outro modo, Foucault (2013) mostra como, historicamente, os grandes modelos de encarceramento surgiram com a finalidade de reprimir a mendicância e a ociosidade. Não foi por acaso que, além da vigilância contínua, o trabalho se tornou obrigatório na pena de detenção. Destinada, em sua origem, a vagabundos, mendigos etc., a prisão instituiu uma espécie de pedagogia do trabalho:

Essa pedagogia tão útil reconstituirá no indivíduo preguiçoso o gosto pelo trabalho, recolocá-lo-á por força num sistema de interesses em que o trabalho será mais vantajoso que a preguiça, formará em torno dele uma pequena sociedade reduzida, simplificada e coercitiva onde aparecerá claramente a máxima: quem quer viver tem que trabalhar (FOUCAULT, 2013, p. 117-118).

A detenção se tornou a pena por excelência entre o fim do século 18 e o início do século 19 , exatamente no período de emergência e desenvolvimento da sociedade capitalista industrial ${ }^{2}$. A obviedade da prisão, diz 
Foucault (2013), fundamenta-se, em primeiro lugar, na privação de liberdade, que permite quantificar a pena segundo o tempo (anos, meses e dias). Mas ela se fundamenta também em seu papel corretivo, como aparelho para transformar os indivíduos. É o duplo fundamento da prisão: jurídico-econômico e técnico-disciplinar. A prisão moderna, portanto, é contemporânea da Revolução Industrial.

Nesse contexto, a utilidade do trabalho penal não é diretamente econômica, não é a obtenção de lucro, mas o estabelecimento de uma relação de poder cuja finalidade é fabricar operários dóceis e produtivos. Numa palavra, trata-se de transformar o detento em trabalhador assalariado. "Se, no fim das contas, o trabalho da prisão tem um efeito econômico, é produzindo indivíduos mecanizados segundo as normas gerais de uma sociedade industrial" (FOUCAULT, 2013, p. 229).

A grande indústria tende a aumentar o número de assalariados e submeter ao comando do capital todos os membros da família do trabalhador, de tal maneira que "[...] o trabalho feminino e infantil foi a primeira palavra de ordem da aplicação capitalista da maquinaria!” (MARX, 2013, p. 468). Daí a Revolução Industrial ter sido acelerada pela expansão das leis fabris, isto é, a limitação e regulamentação do trabalho de mulheres, adolescentes e crianças (duração, início e término, pausas etc.).

Não apenas o valor da força de trabalho diminui com a apropriação do trabalho feminino e infantil pelo capital $^{3}$. Mas ocorre, ao lado da maior concentração dos meios de produção, uma maior concentração de trabalhadores assalariados; para dizer com Foucault (2013), uma acumulação de homens simultânea à acumulação de capital. Numa conjuntura histórica de explosão demográfica e crescimento dos aparelhos de produção, a disciplina cumpre uma tarefa essencial: permite ajustar o trabalhador e seu corpo ao movimento contínuo da máquina industrial. Por isso, o desenvolvimento da economia capitalista fez apelo ao poder disciplinar:

\begin{abstract}
Na verdade os dois processos, acumulação de homens e acumulação de capital, não podem ser separados; não teria sido possível resolver o problema da acumulação de homens sem o crescimento de um aparelho de produção capaz ao mesmo tempo de mantê-los e de utilizá-los; inversamente, as técnicas que tornam útil a multiplicidade cumulativa de homens aceleram o movimento de acumulação de capital. Em um nível menos geral, as mutações tecnológicas do aparelho de produção, a divisão do trabalho, e a elaboração das maneiras de proceder disciplinares mantiveram um conjunto de relações muito próximas. Cada uma das duas tornou possível a outra, e necessária: cada uma das duas serviu de modelo para a outra (FOUCAULT, 2013, p. 208).
\end{abstract}

A divisão capitalista do trabalho exige disciplina. Marx (2013) observou isso muito bem ao comparar a disciplina de quartel com o código fabril. Na fábrica dominada pela maquinaria, onde o patrão é o legislador absoluto, existe um código disciplinar que estabelece o que o operário deve fazer e o que ele não pode fazer. Em caso de inobservância, punições como multas e descontos de salário. Assim como o quartel está dividido entre soldados e suboficiais, a fábrica tem sua divisão entre trabalhadores manuais e capatazes. "No lugar do chicote do feitor de escravos", diz Marx (2013, p. 496), "surge o manual de punições do supervisor fabril".

Segundo Foucault (2013), um dos instrumentos da disciplina, ao lado do exame e da vigilância, é a sanção normalizadora. Um aspecto muito importante é o aspecto rentável da sanção normalizadora, mesmo quando ela é transgredida: “Todas as punições se convertem, naturalmente, em multas pecuniárias e descontos de salário, e a sagacidade legislativa desses Licurgos fabris faz com que a transgressão de suas leis lhes resulte, sempre que possível, mais lucrativa do que sua observância” (MARX, 2013, p. 496).

A disciplina estabelece um pequeno mecanismo penal ou uma micropenalidade, qualificando e reprimindo um conjunto de comportamentos tidos como desviantes. Mas ela traz uma maneira específica de punir: os castigos disciplinares pretendem ter um efeito corretivo, priorizando o exercício, o treinamento, a repetição:

Na oficina, na escola, no exército funciona como repressora toda uma micropenalidade do tempo (atrasos, ausências, interrupções das tarefas), da atividade (desatenção, negligência, falta de zelo), da maneira de ser (grosseria, desobediência), dos discursos (tagarelice, insolência), do corpo (atitudes 'incorretas', gestos não conformes, sujeira), da sexualidade (imodéstia, indecência). Ao mesmo tempo é utilizada, a título de punição, toda uma série de processos sutis, que vão do castigo físico leve a privações ligeiras e a pequenas humilhações (FOUCAULT, 2013, p. 171-172).

A par disso, com o advento da grande indústria e da divisão do trabalho que a acompanha, o capital desenvolve uma função de vigilância e de controle, a qual deve integrar o processo de produção. Uma vigilância intensa e contínua, que fica a cargo de um pessoal especializado e que mira o operário o tempo todo, observando sua destreza, rapidez, zelo e comportamento. Nos termos de Foucault (2013, p. 169): “A vigilância se torna um operador econômico decisivo, na medida em que é ao mesmo tempo uma peça interna no aparelho de produção e uma engrenagem específica do poder disciplinar”. 
Com efeito, a maquinaria exige a disciplina e esta última é funcional à primeira. A disciplina distribui os indivíduos no espaço, fixando cada indivíduo no seu lugar, dividindo e localizando os corpos segundo o princípio do "quadriculamento" (FOUCAULT, 2013). Por meio dela, na fábrica, pode-se distribuir e articular os trabalhadores em torno de um aparelho de produção, de modo a tornar o espaço fabril útil e produtivo. Desse modo é possível alinhar a força de trabalho entre as diversas máquinas, submetendo os corpos singulares à dinâmica mecanizada da produção industrial.

Todo trabalho na máquina exige instrução prévia do trabalhador para que ele aprenda a adequar seu próprio movimento ao movimento uniforme e contínuo de um autômato. Como a própria maquinaria coletiva constitui um sistema de máquinas diversas, que atuam simultânea e combinadamente, a cooperação que nela se baseia exige também uma distribuição de diferentes grupos de trabalhadores entre as diversas máquinas (MARX, 2013,p. 492).

A divisão do trabalho na grande indústria pressupõe a cooperação entre os trabalhadores e grupos de trabalhadores. A maquinaria, para Marx (2013), funciona apenas com base no trabalho coletivo ou combinado. Eis aqui mais uma função do poder disciplinar: a composição de forças. A disciplina permite articular os corpos uns com os outros, extrair deles a máxima força e fazê-los trabalhar em conjunto. "Não há um só momento da vida de que não se possa extrair forças”, diz Foucault (2013, p. 159), “desde que se saiba diferenciá-lo e combiná-lo com outros".

\section{A disciplina e o tempo}

Outra função da disciplina no modo de produção capitalista: permite capitalizar o tempo, fazer bom uso dele, torná-lo mais rentável. Marx (2013) mostrou que a maquinaria é o meio mais poderoso para prolongar a jornada de trabalho, transformando todo o tempo de vida do trabalhador em tempo de trabalho ${ }^{4}$. E quando a jornada de trabalho é legalmente reduzida, a maquinaria provoca, em contrapartida, a intensificação do ritmo de trabalho, ou seja, um preenchimento mais denso dos poros do tempo de trabalho. Como sugere Marx (2013, p. 482-483): "A hora mais intensa da jornada de trabalho de 10 horas encerra tanto ou mais trabalho, isto é, força de trabalho despendida, que a hora mais porosa da jornada de trabalho de 12 horas".

Economizar tempo, quer dizer, trabalhar mais no mesmo período de tempo, este parece ser o lema da sociedade capitalista. Para aumentar o grau de intensidade do trabalho, o capital utiliza formas de pagamento como, por exemplo, o salário por peça. Mas não há dúvida de que o movimento acelerado e contínuo das máquinas exige do operário a mais rigorosa disciplina. É preciso mais esforço, mais atenção, mais regularidade, mais rapidez, mais eficiência, pois, afinal, não se pode perder um só instante do tempo de trabalho.

As disciplinas devem ser vistas também como aparelhos para adicionar e capitalizar o tempo dos indivíduos, cujas técnicas possibilitam uma nova maneira de gerir o tempo e torná-lo útil. Um corpo disciplinado deve aprender a otimizar o tempo: "No bom emprego do corpo, que permite um bom emprego do tempo, nada deve ficar ocioso ou inútil: tudo deve ser chamado a formar o suporte do ato requerido" (FOUCAULT, 2013, p. 147).

Se o poder disciplinar se ocupa, fundamentalmente, do controle do tempo, é também sobre a extração máxima do tempo de trabalho que se instala o movimento do capital. Segundo Marx (2011, p. 588-589): “o próprio capital é a contradição em processo, [pelo fato] de que procura reduzir o tempo de trabalho a um mínimo, ao mesmo tempo em que, por outro lado, põe o tempo de trabalho como única medida e fonte da riqueza".

Um verdadeiro complexo institucional realiza esse processo de sequestro do tempo, de modo a conformar os indivíduos de acordo com o tempo útil ao capitalismo, ou ainda, subordinar a totalidade do tempo de existência dos indivíduos a este modo de produção. "Devemos ainda nos admirar que a prisão se pareça com as fábricas, com as escolas, com os quartéis, com os hospitais, e todos se pareçam com as prisões?" (FOUCAULT, 2013, p. 214).

Foucault (2001, p. 125) põe em questão os elementos cruciais da relação entre capitalismo e poder disciplinar: "Para haver sobre-lucro é preciso haver sub-poder. É preciso que, ao nível mesmo da existência do homem, uma trama de poder político microscópico, capilar, se tenha estabelecido, fixando os homens ao aparelho de produção, fazendo deles agentes da produção, trabalhadores". Essa proposta analítica indica que se observe a trama real das relações de poder, presentes no cotidiano do capitalismo como relação social que produz tudo, inclusive formas de existência. Foucault (2001, p. 116) também mostra como o tempo de vida foi transformado em tempo de trabalho:

É preciso que o tempo dos homens seja oferecido ao aparelho de produção; que o aparelho de produção possa utilizar o tempo de vida, o tempo de existência dos homens. É para isso e desta forma que o controle 
se exerce. São necessárias duas coisas para que se forme a sociedade industrial. Por um lado, é preciso que o tempo dos homens seja colocado no mercado, oferecido aos que o querem comprar, e comprá-lo em troca de um salário; e é preciso, por outro lado, que este tempo dos homens seja transformado em tempo de trabalho. É por isso que em uma série de instituições encontramos o problema e as técnicas da extração máxima do tempo.

A genealogia das relações de poder nos esclarece essa assertiva marxiana: "economia de tempo, a isso se reduz afinal toda economia" (MARX, 2011, p. 119).

\section{Considerações Finais}

As complexas relações presentes no sistema capitalista têm como elemento constituinte as relações de poder disciplinar. Antes que numa posição de mero efeito ou epifenômeno, estas relações de poder são necessárias e estratégicas para o desenvolvimento do capitalismo que se caracteriza como um modo de produção que produz tudo, inclusive formas de vida.

As análises acima demonstram que a produção do lucro e a produção do corpo do trabalhador útil ao capitalismo foram processos coetâneos, essencialmente conectados, articulando para isso não apenas um novo modo de produzir, mas também um multifacetado sistema de controle indispensável à extração da mais-valia e do lucro, bem como ao assujeitamento dos indivíduos a um processo intensificado de exploração e subordinação: “A disciplina aumenta as forças do corpo (em termos econômicos de utilidade) e diminui essas mesmas forças (em termos políticos de obediência)" (FOUCAULT, 2013, p. 133-134). O efeito dela, portanto, é fabricar corpos dóceis, ou seja, úteis e obedientes. No modo de produção capitalista, a disciplina funciona como técnica que fabrica indivíduos-máquinas, tornando-se, assim, um elemento essencial para a acumulação do capital.

\section{Referências}

FOUCAULT, M. Vigiar e Punir: nascimento da prisão. Tradução de Raquel Ramalhete. Petrópolis/RJ: Vozes, 2013. . A Verdade e as Formas Jurídicas. Tradução de Roberto Cabral de Melo Machado e Eduardo Jardim Morais Rio de Janeiro: Nau ed., 2001.

MARX, K. O Capital: crítica da economia política. Tradução de Rubens Enderle. São Paulo: Boitempo, 2013 (Livro I). . Grundrisse: manuscritos econômicos de 1857-1858: esboços da crítica da economia política. Tradução de Mário Duayer e Nélio Schneider. São Paulo: Boitempo; Rio de Janeiro: UFRJ, 2011.

\section{Notas}

1 "O Panóptico é uma máquina de dissociar o par ver-ser visto: no anel periférico, se é totalmente visto, sem nunca ver; na torre central, vê-se tudo, sem nunca ser visto" (FOUCAULT, 2013, p. 191).

2 "Na passagem dos dois séculos, uma nova legislação define o poder de punir como uma função geral da sociedade queé exercida da mesma maneira sobre todos os seus membros, e na qual cada um deles é igualmente representado; mas, ao fazer da detenção a pena por excelência, ela introduz processos de dominação característicos de um tipo particular de poder. Uma justiça que se diz 'igual', um aparelho judiciário que se pretende 'autônomo', mas que é investido pelas assimetrias das sujeições disciplinares, tal é a conjunção do nascimento da prisão, 'pena das sociedades civilizadas"” (FOUCAULT, 2013, p. 217-218).

3 "O valor da força de trabalho estava determinado pelo tempo de trabalho necessário à manutenção não só do trabalhador adulto individual, mas do núcleo familiar. Ao lançar no mercado de trabalho todos os membros da família do trabalhador, a maquinaria reparte o valor da força de trabalho do homem entre sua família inteira. Ela desvaloriza, assim, sua força de trabalho" (MARX, 2013, p. 468).

4 "Daí este notável fenômeno na história da indústria moderna, a saber, de que a máquina joga por terra todas as barreiras morais e naturais da jornada de trabalho. Daí o paradoxo econômico de que o meio mais poderoso para encurtar a jornada de trabalho se converte no meio infalível de transformar todo o tempo de vida do trabalhador e de sua família em tempo de trabalho disponível para a valorização do capital” (MARX, 2013, p. 480).

\section{Gustavo Meneghetti}

gutomeneghetti84@yahoo.com.br

Mestre e doutorando em Serviço Social pela Universidade Federal de Santa Catarina (UFSC)

Assistente Social do Tribunal de Justiça de Santa Catarina (TJSC) 


\section{Simone Sobral Sampaio}

simone.s@ufsc.br

Doutora em Serviço Social pela Universidade Federal do Rio de Janeiro (UFRJ)

Docente do Departamento de Serviço Social da Universidade Federal de Santa Catarina (DSS/UFSC)

\section{Tribunal de Justiça de Santa Catarina}

Fórum da Comarca de Seara

Rua do Comércio, 171, Centro

Seara - Santa Catarina - Brasil

CEP: 89770-000

\section{UFSC}

Campus Reitor João David Ferreira Lima

Bairro Trindade

Florianópolis - Santa Catarina - Brasil

CEP: 88040-970 